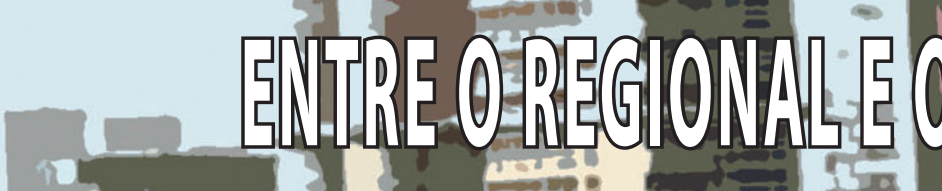

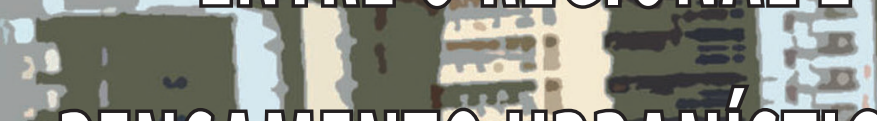

5

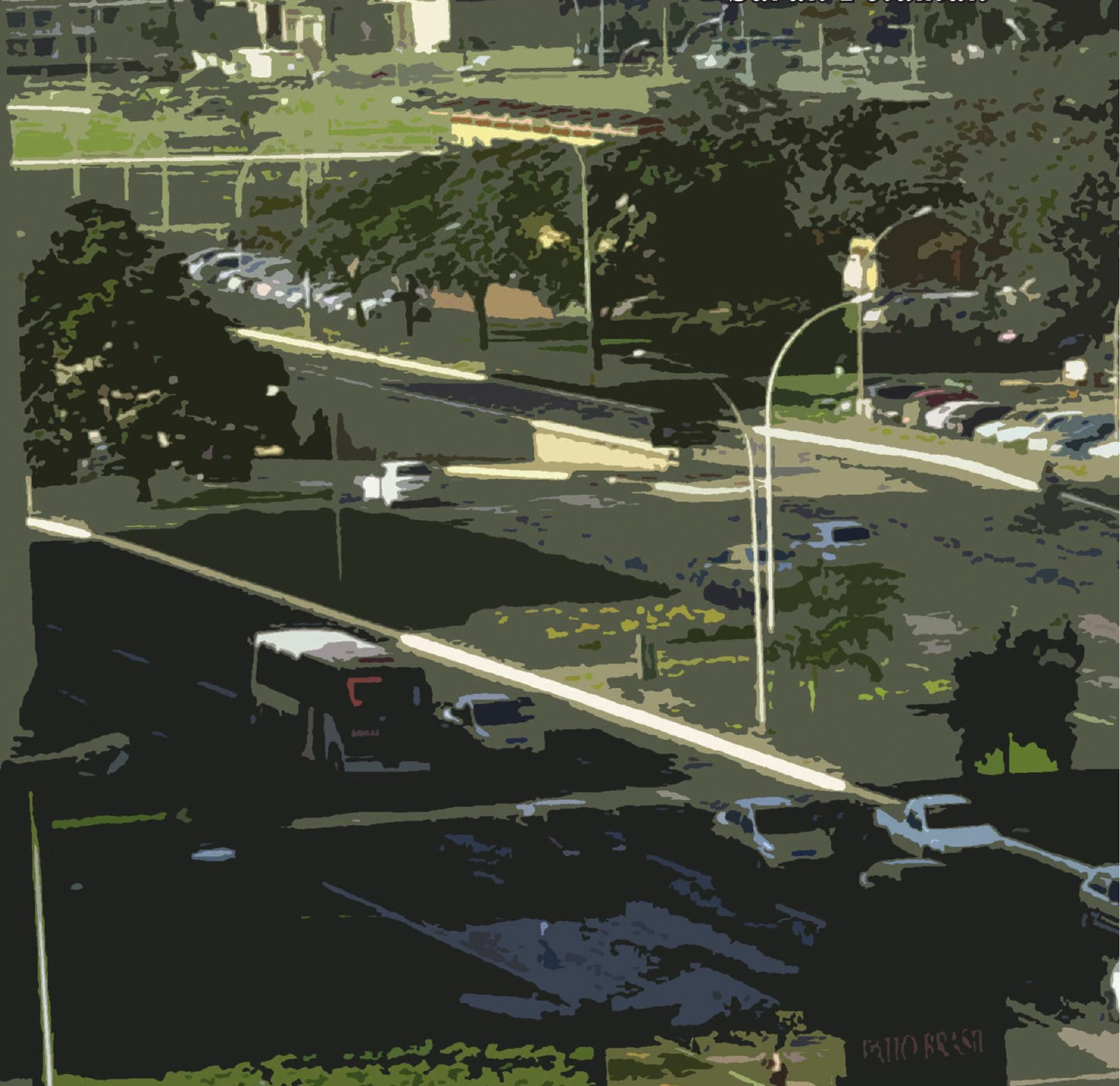

\title{
Sarah Feldman
}



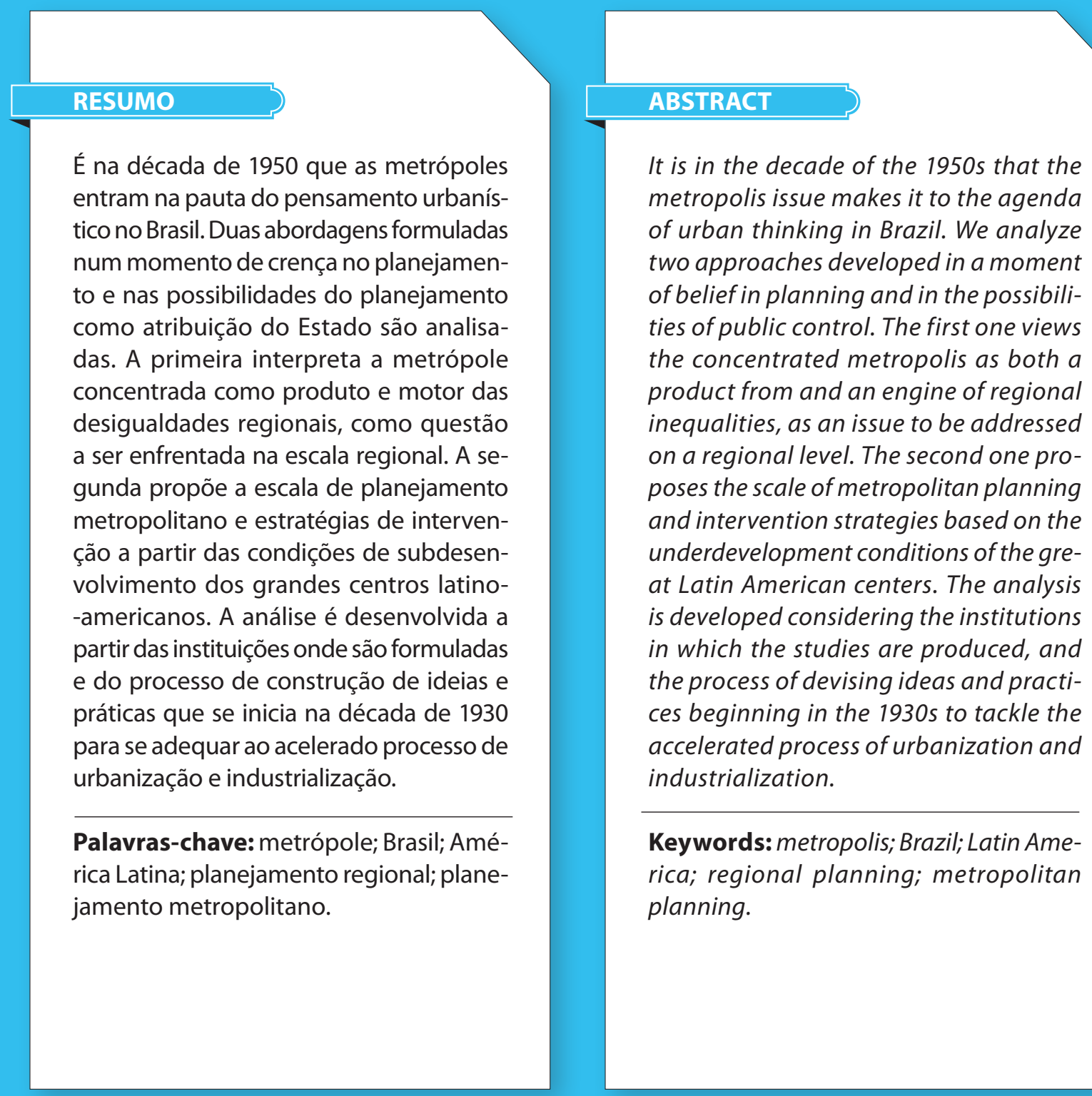

Keywords: metropolis; Brazil; Latin America; regional planning; metropolitan planning. 


\section{UM CICLO DE CONSTRUÇÃO DE IDEIAS E PRÁTICAS URBANÍSTICAS}

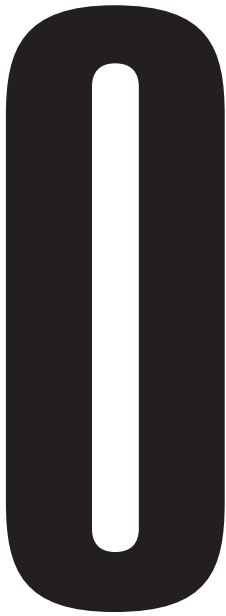

período entre as décadas de 1930 e 1970 configura um ciclo de construção de ideias e de práticas urbanísticas no Brasil que tem por base dois aspectos emblemáticos do século XX. É o período em que o Estado é assumido como principal agente do planejamento,e a urbanização movida pela industrialização constitui a metrópole conurbada e concentrada - a "metrópole gigante"

É necessário qualificar e matizar esse ciclo marcado por movimentos de naturezas diversas. Dois períodos autoritários intercalados por um período democrático compõem o quadro jurídico-institucional, o que será determinante em mudanças nas relações entre técnica e política que se estabelecem na administração pública. Ao longo dessas quatro décadas, instituições são criadas e extintas em intervalos de tempo por vezes muito pequenos, e práticas não são plenamente consumadas.

Mudanças e interrupções expressam a não linearidade do processo, os embates, os conflitos, as múltiplas temporalidades que a dinâmica urbana contém. Assim como ideias persistem, avançam,

1 Entre vários termos utilizados pelos historiadores da cidade e do urbanismo para qualificar a metrópole do século XX, destacam-se: giant metropolis (Peter Hall); giant cities (Anthony Sutcliffe); centralized industrial metropolis (Robert Fishman). recuam ou são revistas, as práticas se acomodam, se deslocam, se transformam nos diferentes contextos políticos, econômicos, sociais, culturais, em durações diversas. Ou, como afirma Lepetit (2001, p. 145), a cidade "nunca é absolutamente sincrônica: o tecido urbano, o comportamento dos citadinos, as políticas de planificação urbanística, econômica ou social desenvolvem-se segundo cronologias diferentes".

As mudanças que ocorrem no Brasil a partir da década de 1930 forçam a reconstrução de saberes e práticas instalados no campo do urbanismo. A expressão mais contundente das relações entre industrialização e urbanização a partir dos anos 1930 se encontra no clássico texto de Francisco Oliveira (1982, p. 41) "O Estado e o Urbano". Segundo o autor, com a divisão social do trabalho e a expansão capitalista sendo comandada pela indústria, a industrialização no Brasil "vai ter que se fazer imediatamente urbana e excepcionalmente urbana".

Em sintonia com o novo estágio da realidade urbano-industrial, é no contexto de centralização política e financeira da era Vargas que se inicia a construção e difusão da pauta urbanística que, até os anos de 1970, será perseguida, ampliada, trans-

SARAH FELDMAN é professora livre-docente do Instituto de Arquitetura e Urbanismo da USP, pesquisadora do CNPq, membro da Rede de Pesquisa Urbanismo no Brasil e autora de Planejamento e Zoneamento (Edusp/Fapesp). 
formada e atualizada pelo trabalho persistente de várias gerações de urbanistas.

Profissionais atuantes em órgãos municipais e estaduais, nas universidades, em entidades profissionais, nos congressos e em revistas especializadas propõem e reivindicam uma mudança radical na concepção do urbanismo. A concepção de urbanismo deve ser alargada, repensada em suas várias dimensões.

Como questão de administração, "na acepção mais ampla da palavra" (Azevedo, 1935, p. 104); como uma questão técnica "de novas dimensões" (Baptista de Oliveira, 1937); como questão multidisciplinar - "uma síntese, que exige conhecimentos de arquitetura, engenharia, paisagismo, leis, governo e administração, sociologia e economia" (Anhaia Mello, 1933, p. 212) .E como questão multiescalar: "a sciencia do urbanismo tem por objetivo dar uso apropriado a todo o terreno urbano", e o problema da terra deve ser abordado em termos de regiões ou unidades econômicas completas, e "não em termos de cidades ou unidades políticas fictícias ou arbitrárias" (Anhaia Mello , 1932, p. 235 ).

A importância da década de 1930 está na mobilização no campo do urbanismo assim como em outros que atuam na formação de conhecimento sobre a realidade urbano-industrial, como a sociologia e a geografia, que preparam as condições para as trocas disciplinares que se realizam nas décadas seguintes.

As práticas instaladas ao longo da era Vargas não acompanham a perspectiva renovadora da mobilização. A formação de uma elite burocrática desvinculada da política colocada pelo projeto de modernização da administração pública empreendido por Vargas repercute profundamente nos espaços de exclusiva atuação dos urbanistas. Nesses espaços o planejamento é concebido como uma atividade estritamente consultiva, distanciada da política e da atividade cotidiana da administração².

É no período democrático, mais especificamente na década de 1950 , que as metrópoles e áreas metropolitanas entram na pauta do debate urbanístico no Brasil. Essa entrada se dá, por um lado,

2 Sobre as repercussões da reforma administrativa de Vargas nos órgãos de planejamento municipais a partir da década de 1940, consultar Feldman (2005). através de estudos desenvolvidos por urbanistas vinculados a universidades e a instituições que se organizam fora da administração, por outro lado, no âmbito da participação de urbanistas brasileiros nas conferências, seminários e demais atividades promovidas pela Organização dos Estados Americanos (OEA) e pela Unión Panamericana (UP).

No intervalo de menos de duas décadas entre o final do Estado Novo (1945) e o golpe militar de 1964, no contexto democratizante da Constituição de 1946, são criadas instituições externas à administração, que, através da realização de cursos, da elaboração de estudos, da introdução de novas metodologias e práticas, da formação de equipes multidisciplinares, colaboram para a formação de quadros técnicos. Essas instituições atuam no campo da assistência técnica aos municípios, na perspectiva de criar ou fortalecer órgãos de planejamento, e introduzem novas referências que se distanciam da dimensão tecnicista entranhada na administração pública.

Destacam-se, nesse sentido, a Sociedade de Análise Gráfica e Mecanográfica Aplicada aos Complexos Sociais (Sagmacs), em 1947, em São Paulo, criada pelo padre francês Joseph Louis Lebret, vinculado ao movimento Economie et Humanisme; o Centro de Pesquisas e Estudos Urbanísticos (CPEU), criado em 1955 junto à FAU-USP, por iniciativa de Luis Inácio de Anhaia Mello; o Centro de Estudos de Planejamento Urbano e Regional (Cepur), criado por Antonio Bezerra Baltar no início da década de 1960 , junto à Universidade do Recife; e o Instituto Brasileiro de Assistência aos Municípios (Ibam), criado em 1952, no Rio de Janeiro, no âmbito do Programa de Cooperação Técnica em Administração Pública com a United States Agency for International Development (Usaid). Em 1951, é criada a Comissão Interestadual da Bacia Paraná-Uruguai (CIBPU), uma instituição supragovernamental, a partir de um convênio entre sete governos ${ }^{3}$ da região sudoeste do país ${ }^{4}$.

3 O convênio foi realizado entre os governos de São Paulo, Santa Catarina, Paraná, Rio Grande do Sul, Mato Grosso, Goiás e Minas Gerais.

4 Há um conjunto de estudos que abordam essas instituições: Leme \& Lamparelli (2001); Pontual (2011); Angelo (2010); Cestaro (2009); Chiquito (2001); Mello (1993). 
Paralelamente a esse processo, assim como os demais países da América Latina, o Brasil se inclui no circuito privilegiado de experts internacionais. Desde o final da década de 1940, a explosão urbana no Terceiro Mundo torna-se o centro das atenções nas teorias da modernização, nas políticas de desenvolvimento, na formulação do conceito de subdesenvolvimento e na concepção da problemática urbana e regional (Gorelik, 2005).

A criação da Organização das Nações Unidas (ONU), em 1945, e da Organização dos Estados Americanos (OEA), em 1948, garante o principal suporte institucional para que profissionais de diferentes campos disciplinares e de diferentes países se engajem na missão de cooperação e assistência técnica às regiões subdesenvolvidas. Em 1950, a Comissão Econômica para a América Latina e o Caribe (Cepal), criada pela ONU em 1948, com sede em Santiago do Chile, se instala no Brasil.

O Point Four Program, criado por Harry Truman, em 1949, para troca de conhecimento técnico e experiência com os países subdesenvolvidos, foi a porta de entrada, no Brasil, para consultores da ONU, OEA, UP, Fundação Ford, Fundação Rockefeller, entre outras, desenvolverem trabalhos em várias regiões do país. No campo do planejamento, esses experts realizaram estudos acadêmicos, como o de Francis Violich, Cities of Latin America. Housing and Planning to the South, publicado em 1944; ministraram cursos, como os de John Friedmann, na Escola Brasileira de Administração, entre 1955 e 1958; participaram da elaboração de planos, como Violich, em São Paulo (1968), e Friedmann, na Bahia (1961) e no Pará (1971) .

No sentido contrário, o Point Four viabilizou a participação do Brasil em fóruns onde o planejamento da metrópole da América Latina foi problematizado, como nas Conferências Interamericanas - órgão supremo da OEA - e principalmente no Centro Interamericano de Vivienda y Planeamien-

5 Os dois americanos desenvolvem suas carreiras como consultores paralelamente ao vínculo com a universidade. Violich teve papel fundamental na criação do City and Regional Planning Department da Universidade da Califórnia-Berkeley, em 1948, e na formação do College of Environmental Design, dez anos depois. Friedmann foi fundador do Program for Urban Planning na Graduate School of Architecture and Planning da Universidade da Califórnia-Los Angeles, nos anos de 1960. to (Cinva), criado em 1951 através de um Programa de Cooperação Técnica da OEA junto à Universidade Nacional da Colômbia, em Bogotá.

A década de 1950 pode ser entendida como um momento de formulação e de proposição de caminhos para o planejamento no Brasil, a partir de desafios que vinham sendo colocados pelos urbanistas desde a década de 1930 e dos novos desafios que a realidade urbana colocava diante da consolidação da "metrópole gigante". A diversidade dos lugares em que se originam as propostas, de modo geral lugares de debate e reflexão coletiva, revela um momento profícuo do pensamento urbanístico.

As duas abordagens sobre a metrópole formuladas ao longo dos anos de 1950 fornecem um panorama da reflexão sobre o planejamento em geral e em relação à condição da metrópole, em particular. Essas abordagens antecedem a institucionalização de políticas relacionadas às áreas metropolitanas na esfera federal, a partir de 1964, no contexto do regime autoritário.

O ciclo iniciado na década de 1930 se encerra em 1974 com a criação da primeira instituição federal com foco específico nas áreas metropolitanas - a Comissão Nacional de Regiões Metropolitanas e Política Urbana (CNPU). Sua finalidade é acompanhar a implantação das regiões metropolitanas definidas entre 1973 e 1974 e também propor diretrizes, estratégias e instrumentos da Política Nacional de Desenvolvimento Urbano (Decreto 74.156/1974).

Define-se, nesse momento, a opção pela figura da Região Metropolitana - nem regional e nem metropolitana, nos termos colocados pelos urbanistas ao longo da década de 1950.

\section{A DÉCADA DE 1950: A CRENÇA NO CONTROLE PÚBLICO E NO} PLANEJAMENTO DA METRÓPOLE GIGANTE

Na década de 1950, o traço mais marcante do processo de urbanização no Brasil do século XX - a conurbação configurando áreas metropolitanas - já é um fato. Ao longo da década, a população urbana brasileira cresceu $60 \%$, e $1 / 3$ desse 
incremento populacional se instala em áreas metropolitanas. Na Região Sudeste, onde se situam as duas únicas cidades com mais de um milhão de habitantes - São Paulo e Rio de Janeiro -, a taxa de urbanização já está próxima de $60 \%$. São Paulo está no centro do processo de mudanças qualitativas e quantitativas da indústria e supera, ao longo dessa década, a população do Rio de Janeiro. Nos grandes centros urbanos do país, as periferias já estão consolidadas com as precariedades peculiares às diferentes regiões.

A década de 1950 pode ser considerada o momento de maior crença no planejamento e nas possibilidades do planejamento como atribuição privilegiada do Estado. No Brasil, é o momento de um otimismo modernizador, que se insere no quadro do chamado nacional-desenvolvimentismo e se expressa no Plano de Metas, na criação da Sudene e na mudança da capital para Brasília. Esse otimismo que se instala a partir do pós-guerra antecede a inversão para o pessimismo e a crítica radical ao planejamento que se dissemina pelo mundo ocidental no final dos anos de 1970 (Sutcliffe, 1984, p. 2). Na América Latina essa crença antecede o que Gorelik (2005) denomina "a construção cultural da cidade latino-americana", quando esta começa a ser discutida a partir de suas impossibilidades.

Nos dois movimentos de reflexão e problematização da metrópole ao longo da década de 1950 há a convicção da possibilidade de intervir e reverter o crescimento descontrolado dos grandes centros através do planejamento.

\section{Planejar a região: a metrópole concentrada como produto e motor das desigualdades}

\section{regionais}

Nos estudos desenvolvidos na primeira metade dos anos de 1950, o eixo direcionador é o questionamento da organização da metrópole concentrada. Não se trata necessariamente da negação da metrópole, mas de interferir no processo de concentração demográfica e de concentração industrial. A metrópole concentrada é colocada como produto e motor das desigualdades regionais, como questão a ser enfrentada na escala regional.

Destacam-se dois estudos elaborados por urbanistas vinculados a universidades: Diretrizes de um Plano Regional para o Recife, tese apresentada por Antonio Bezerra Baltar, em 1951, no concurso para a cátedra de Urbanismo e Arquitetura Paisagística da Universidade do Recife, e Elementos Básicos para o Planejamento Regional de São Paulo, estudo apresentado por Luis Inácio de Anhaia Mello para a Comissão Orientadora do Plano da Cidade de São Paulo, como representante da Universidade de São Paulo, em 1954. E, dentre os trabalhos desenvolvidos por instituições externas à administração, os estudos e projetos desenvolvidos para a região delimitada pela bacia hidrográfica Paraná-Uruguai, pela Comissão Interestadual da Bacia Paraná-Uruguai - CIBPU, a partir de 1952, nos quais a Sagmacs esteve envolvida.

O planejamento regional introduz um conjunto de novas questões: a superação do limite político administrativo para a demarcação de áreas de planejamento; e a necessidade de considerar determinantes geográficos, econômicos, as potencialidades de recursos regionais, assim como os avanços da técnica no processo de planejamento. A introdução da dimensão regional não se dá apenas como uma ampliação de escala territorial.

As principais referências nesses estudos são o Greater London Plan (1944), coordenado por Patrick Abercrombie, e os instrumentos urbanísticos criados na Inglaterra para sustentação do Town and Country Planning Act de 1947. E, dos Estados Unidos, os trabalhos desenvolvidos pela Tenessee Valley Authority (TVA), criada em 1933, e todo o repertório mobilizado pelo New Deal da era Roosevelt (1933-37) e no governo de Harry Truman (1945-53). Nos dois continentes, trata-se de vertentes do pensamento urbanístico das primeiras décadas do século XX reinterpretadas no período otimista do pós-guerra e dotadas de forte conteúdo social.

Além dessas, inclui-se a "Charte de L'Aménagement", documento elaborado pelo grupo Economie et Humanisme em 1952 durante uma semana de estudos em La Tourette. Por esse conjunto de referências perpassa o forte vínculo com os conceitos 
e princípios desenvolvidos por Patrick - a perspectiva de planejamento regional, o pleno aproveitamento dos recursos naturais, o profundo conhecimento da realidade, seus vínculos com a botânica e com a geografia. Não por acaso o termo "conurbation" é cunhado por Geddes, em 1914, para o processo de crescimento urbano articulado a uma região, que observa em Londres.

Ainda que definam escalas regionais distintas e apresentem diferenças nas concepções de organização do espaço regional, o elemento unificador dos estudos desenvolvidos no Brasil é a associação entre planejamento e desenvolvimento. Nessa associação expressam a convicção de que o controle público é possível, e as grandes cidades podem ser renovadas, reorganizadas e redistribuídas, de forma a tornar eficiente a organização territorial e superar as desigualdades regionais.

\section{Planejamento e habitação: intervenção na metrópole}

\section{latino-americana}

A problematização da metrópole latino-americana no âmbito das organizações interamericanas tem sua raiz na questão da habitação. No final da década de 1930, a habitação é reconhecida como um problema comum e um dos maiores que afetam os países americanos ${ }^{6}$. A partir desse momento, amplia-se na OEA e na UP a organização institucional que associa habitação e planejamento com a participação dos experts internacionais. Na década de 1940 são criados um programa permanente de pesquisa e informação sobre habitação ${ }^{7}$ e uma Divisão de Habitação e Planejamento junto à UP.

O Cinva ${ }^{8}$, na década de 1950 , alavanca esse processo e passa a agregar atividades de ensino, pesquisa, intercâmbio, assistência em habita-

6 No Primer Congreso Panamericano de la Vivienda Popular, organizado pela UP e pelo governo argentino, em 1939, pela primeira vez a habitação foi o tema exclusivo em um congresso continental, e foi abordada em seus aspectos econômico, higiênico, social, financeiro, jurídico, legislativo, arquitetônico, construtivo e urbanístico.

7 Violich foi contratado como housing and city planning specialist at the UP e dirigiu o programa de 1943 a 1947, quando foi substituído por Anatole A. Solow, da Universidade de Pittsburgh. ção, arquitetura e urbanismo, desenvolvimento de trabalhos na área de planejamento e um curso de pós-graduação sobre o tema (Restrepo, 2003).

Nesse processo são envolvidos profissionais atuantes em planejamento nos vários países latino-americanos que agregam aos princípios técnicos dos experts um amplo conhecimento da realidade das metrópoles latino-americanas.

Métodos de produção, construção e financiamento habitacional, inventário e definição de eliminação do déficit, reabilitação de bairros insalubres, planejamento, instituições, padrões de urbanização e zoneamento foram objeto de uma vasta gama de atividades e encontros em todo o continente ${ }^{9}$. Políticas, programas e instrumentos de intervenção são formulados, ampliando o espaço do planejamento. Em 1958 é realizado um seminário voltado para urbanistas da América Latina e Central - Seminario de Técnicos y Funcionarios en Planeamiento Urbano.

Realizado em Bogotá, nele são definidas estratégias de planejamento e habitação profundamente enraizadas na realidade da metrópole da América Latina. A migração, as altas taxas de crescimento populacional, a especulação, a formação de favelas e habitações precárias e a falta de serviços públicos são apontados como os processos que devem ser superados através da combinação de políticas de planejamento e habitação. As conclusões do seminário geram um documento assumido e assinado por representantes de países da América Latina e da América Central denominado "Carta de Los Andes".

Uma carta assinada por cerca de 40 participantes, dentre os quais Antonio Bezerra Baltar, Newton de Oliveira e Mario Larangeira ${ }^{10}$, que integraram a delegação brasileira, acompanha o

8 Em 1954 o nome é alterado para Centro Interamericano de Vivienda y Planeamiento.

9 O Brasil sediou um dos três seminários regionais sobre questões sociais de habitação e desenvolvimento urbano, em Porto Alegre, em 1951. Os outros dois se realizaram em Quito e em El Salvador, em 1950 (Unión Panamericana, 1952).

10 Antonio Bezerra Baltar, do Recife, e Mario Larangeira, de São Paulo, tinham ligações com a Sagmacs, e Newton de Oliveira, de Salvador, atuava no Instituto de Arquitetos do Brasil. 
documento. Dirigida a los pueblos de America, reafirma a crença no planejamento como instrumento a ser conduzido pelo governo, dentro do mais alto sentido democrático e como a ferramenta mais adequada para superar as grandes dificuldades em consequência do baixo nível de desenvolvimento econômico, político, social e cultural (OEA, 1958).

É introduzida a escala de planejamento metropolitano, além do regional e urbano, para enfrentar os problemas dos grandes centros da América Latina. Constam do documento a necessidade de controle da especulação da terra, que inclui a revisão da fixação dos valores imobiliários, a distribuição da justa proporção dos custos de obras realizadas por entidades públicas entre os proprietários beneficiados, a reserva de terras por parte de entidades do governo para desenvolver programas de habitação social, e impor tributos a lotes que se mantêm injustificadamente sem uso. E, com relação aos moradores de favelas, é proposta a criação de sistemas de ajuda própria ou mútua, com assistência técnica, econômica e social das municipalidades ou de instituições de habitação de interesse social, assim como a possibilidade de utilização de padrões urbanísticos diferenciados na solução dos projetos (OEA, 1958, pp. 18-20).

A "Carta de los Andes" teve ampla difusão entre os urbanistas brasileiros, sendo traduzida e publicada no Brasil em 1960, apenas dois anos após sua formulação.

A abertura do documento das resoluções do Seminário de Habitação e Reforma Urbana organizado pelo Instituto de Arquitetos do Brasil com o apoio do governo federal, realizado no Rio de Janeiro e São Paulo, menos de um ano antes do golpe militar de 1964, situa o problema habitacional no âmbito da América Latina "como resultado das condições de subdesenvolvimento provocadas por fatores diversos, inclusive processos espoliativos, a que se acham submetidos os países latino-americanos".

É nesse seminário que se formaliza o repertório voltado para a intervenção na metrópole latino-americana, tendo como eixo norteador a associação entre habitação e planejamento.

No contexto do regime militar, ainda que tenham sido criadas as Regiões Metropolitanas, sua concepção não se vincula a nenhuma das duas abordagens construídas ao longo da década de 1950. Além disso, os órgãos de abrangência metropolitana não se viabilizam para atuarem no governo e planejamento de um conjunto de municípios, entre outras razões, pela autonomia municipal definida na Constituição de 1967.

Com o fim do regime autoritário, a partir da década de 1980, parte significativa do repertório referente à intervenção nas metrópoles da "Carta de los Andes" estará no centro do ideário urbanístico que se afirma no Brasil. No entanto, apesar de se tornar política pública através do Estatuto da Cidade aprovado em 2001, esse ideário não se vincula nem ao planejamento regional, nem ao planejamento metropolitano, mas ao planejamento municipal.

De fato, a partir da década de 1980, há mudanças profundas no papel do Estado no ideário urbanístico, na conformação das áreas metropolitanas - não mais concentradas, mas dispersas -, e há mudanças também nas dinâmicas demográficas, quantitativas e espaciais, no Brasil. Apesar de um novo ciclo, há permanências nas metrópoles que dão sentido ao resgate, após quase três décadas, de formulações gestadas na década de 1950. Vale a pena resgatar Lepetit (2001, p. 145): a cidade, de fato, "nunca é absolutamente sincrônica". 


\section{BIBLIOGRAFIA}

ANGELO, Michelly. Les Développeurs Louis-Joseph Lebret e a Sagmacs na Formação de um Grupo de Ação para o Planejamento Urbano no Brasil. Tese de doutorado. São Carlos,

IAU-USP, 2010.

ANHAIA MELLO, Luis I. Romero de. O Plano Regional de São Paulo - Uma Contribuição da Universidade para o Estudo de um Código de Ocupação Lícita do Solo. São Paulo, 1954.

. "Urbanismo e suas Normas para Organização de Planos", in Boletim do Instituto de Engenharia n ${ }^{\circ}$ 89. São Paulo, abril de 1933, pp. 209-18.

.A Economica da Terra", in Revista Polytechnica no 105. São Paulo, maio-junho de 1932, pp. 235-41.

AZEVEDO, Washington. A Organização Technica dos Municipios. Rio de Janeiro, Irmãos Pongetti, 1935.

BALTAR, Antonio Bezerra. Diretrizes de um Plano Regional para o Recife. Recife, Editora Universitária, 1951.

BAPTISTA DE OLIVEIRA, Francisco. Noções Elementares de Urbanismo. Juiz de Fora, União Industrial Editora, 1937.

CESTARO, Lucas. Urbanismo e Humanismo: a Sagmacs e o Estudo da Estrutura Urbana da Aglomeração Paulistana. Dissertação de mestrado. São Carlos, EESC-USP, 2009.

CHIQUITO, Elisangela de A. A Comissão Interestadual da Bacia Paraná-Uruguai: do Planejamento de Vale aos Polos de Desenvolvimento. Tese de doutorado. São Paulo, IAU-USP, 2001.

CIBPU - Comissão Interestadual da Bacia do Paraná-Uruguai. Problemas de Desenvolvimento. Necessidades e Possibilidades do Estado de São Paulo. São Paulo, CIBPU, 1954.

COTTAM, Howard R. O Ponto IV no Brasil.

FELDMAN, Sarah. "Planejamento, Desenvolvimento, Habitação: o Brasil no Circuito de Experts Internacionais", in Anais do XII Seminário de História da Cidade e do Urbanismo. Porto Alegre, UFRGS, 2012 (CD-ROM). . Instituições de Urbanismo no Brasil na Década de 1930: Olhar Técnico e Dimensão Urbano-industrial. Tese de livre-docência. São Carlos, EESC-USP, 2008. . Planejamento e Zoneamento. São Paulo, 1947-1972. São Paulo, Edusp/Fapesp, 2005.

FISHMAN, Robert. "Megalopolis Unbound", in Philip Kasinitz. Metropolis. Center an Symbol of our Times. New York, New York University Press, 1995.

FRIEDMANN, John R. P. Introdução ao Planejamento Democrático. Rio de Janeiro, FGV/Ebap, 1959.

. Introdução ao Planejamento Regional (com Referência Especial à Região Amazônica). Rio de Janeiro, EBAP/FGV, 1960.

GORELIK, Adrian. "A Produção da Cidade Latino-Americana", in Tempo Social. Revista de Sociologia da USP, vol. 17, n 1. São Paulo, USP, junho de 2005, pp.111-33.

HALL, Peter. "Metropolis 1890-1940: Challenges and Responses", in Anthony Sutcliffe (ed.). Metropolis 1890-1940. Chicago, University of Chicago Press, 1984, pp.19-66. 
IAB-IPASE. Relatório do Seminário de Habitação e Reforma Urbana. Julho de 1963 (xerox).

LEPETIT, Bernard. "É Possível uma Hermenêutica Urbana?", in Heliana A. Salgueiro. Por uma Nova História Urbana. São Paulo, Edusp, 2001, pp. 137-54.

LEME, M. Cristina; LAMPARELLI, Celso M. "A Politização do Urbanismo no Brasil: a Vertente Católica", in Anais IX Enanpur. Rio de Janeiro, 2001, pp. 675-87.

MELLO, Marcus A. "Municipalismo, Nation-Building e a Modernização do Estado no Brasil", in RCBS ano 8, n 23. São Paulo, outubro de 1993, pp. 85-100.

MINISTÉRIO DAS RELAÇÕES EXTERIORES. O Brasil e os Programas de Assistência Técnica da ONU e da OEA. Distrito Federal, CNAT, 1952.

OLIVEIRA, Francisco de. "O Estado e o Urbano", in Espaço \& Debates, n. 6, São Paulo, jun.-set./1982, pp. 36-54.

OEA - Organización de Estados Americanos. Consejo Interamericano Economico y Social. Seminario de Técnicos y Funcionarios en Planeamiento Urbano - Informe Final. Bogotá, Cinva, 1958.

PONTUAL, Virginia. “O Engenheiro Antonio Bezerra Baltar: Prática Urbanística, Cepur e Sagmacs", in Revista Brasileira de Estudos Urbanos e Regionais, v. 13, n. 1. São Paulo, 2011, pp.151-69.

RESTREPO, Luis Fernando A. "El Cinva e Su Entorno Espacial y Político", in Buru.Mimesis v. 24, n.1, 2003, pp. 59-89.

SCHAFFER, Frank. "The Town and Country Planning Act, 1947", in The Planner, vol. 60, n. 5, May 1974.

SUTCLIFFE, Anthony. "Introduction: Urbanization, Planning and the Giant City", in Anthony Sutcliffe (ed.). Metropolis 1890-1940. Chicago, University of Chicago Press, 1984, pp. $1-18$.

THE DEPARTMENT Of STATE. Point IV Cooperative Program for Aid in the Development of Economically Underdeveloped Areas. 1950.

UNIÓN PANAMERICANA. Informe de la Secretaria del Consejo Economico y Social sobre la Primera Reunión Técnica Interamericana de Vivienda y Planeamiento. Washington DC, Union Panamericana, 1956. . Seminarios Regionales de Asuntos Sociales. Vivienda y Urbanismo. Washington DC, Unión Panamericana, 1952. . Resultados del Primer Congreso Panamericano de la Vivienda Popular. Washington DC, Unión Panamericana, 1939.

VIOLICH, Francis. Cities of Latin America. Housing and Planning to the South. New York, Reinhold Publishing Corporation, 1944. 